\title{
CULTURA CORPORAL E EDUCAÇÃO ESCOLAR INDÍGENA - UM ESTUDO DE CASO
}

\author{
Denise Monteiro de Castro \\ Marcos Garcia Neira \\ mgneira@usp.br \\ Faculdade de Educação da USP \\ Apoio: CNPq
}

\section{RESUMO:}

O presente artigo descreve um estudo de caso de tipo etnográfico que pretendeu identificar as relações entre o patrimônio cultural corporal do povo guarani e a educação escolar. Realizado em uma escola estadual indígena situada no litoral paulista, a investigação recorreu à observação participante, entrevistas com profissionais da escola e registros fotográficos. Os dados, registrados em diários de campo, foram submetidos à descrição crítica e confrontados com a teorização da cultura corporal, da educação indígena e da antropologia. A pesquisa revela a permanência das práticas corporais guaranis no contexto extra-escolar e sua ausência no currículo. Dentre os elementos que permitem entender essa dissonância, destaca-se a questão da identidade étnica, em processo de fragmentação.

Palavras-chave: educação escolar indígena - cultura corporal - educação

\section{CORPORAL CULTURE AND INDIAN SCHOOL EDUCATION? A CASE STUDY}

\begin{abstract}
:
The present article describes a case study of an ethnographic type which intended to identify the relation between the corporal culture patrimony of Guarani people and school education. Conducted in a state Indian school, located in the cost of São Paulo, the investigation made use of participant observation, interview with the school professional and photographic registers. The data, registered in field diaries, were subjected to the critical description and confronted with the theorization of the cultural corporal, Indian educations and anthropology. The research revels the remaining of Guarani corporal practices in the extra-school context and it absence in the curriculum. Among the elements which allow to understand this dissonance, it is highlighted the question of ethnic identity and fragmentation process.
\end{abstract}

Key-words: Indian school education - culture body - education

\section{Introdução}

As características do atual momento histórico no qual a sociedade brasileira busca aprofundar a participação democrática de todos os grupos que a compõem, apontam para o entendimento de que a escola pode ser uma instituição determinante desse processo por meio de um ensino que aborde, valorize e respeite a diversidade cultural.

Há muito, as investigações de Daolio (1995) explicitaram que as diferenças culturais manifestam-se, também, por meio de uma linguagem corporal específica. Cada 
grupo social, ao longo da sua trajetória histórica, produz e reproduz um patrimônio cultural corporal que o distingue dos demais.

Nessa perspectiva, Neira e Nunes (2006) citando Santin (1987), explicitam que o movimento é concebido como linguagem, como forma de comunicação e interação. É pelo patrimônio da cultura corporal ${ }^{1}$ que diferentes grupos manifestam suas formas de ver e entender o mundo, produzem, atribuem e socializam significados.

Tomando como referência a teorização antropológica, o autor afirma que a linguagem corporal resulta das interações sociais e da relação dos homens com o ambiente; seu significado constrói-se em função de diferentes necessidades, interesses e possibilidades corporais presentes nas diferentes culturas, em diferentes épocas da história. Assim, ao brincar, jogar, imitar e criar ritmos, as crianças também se apropriam do repertório da cultura corporal na qual estão inseridas. Depreendemos daí que as instituições educativas deverão favorecer um ambiente social onde a criança se sinta estimulada e segura para manifestar seu repertório de práticas culturais corporais. Quanto menos constrangedor, do ponto de vista dos movimentos, for o espaço educacional, maior será a possibilidade de ampliação de conhecimentos acerca de si mesma, dos outros e do meio em que vive.

Entendemos que a pedagogia da cultura corporal, da mesma forma que as intervenções educativas, não poderão permanecer inalteráveis diante das modificações produzidas no seu entorno social e cultural. Nesse sentido, cada escola deve desenvolver currículos que levem em conta os condicionantes contextuais que configuraram o surgimento e a reprodução de determinadas práticas corporais, bem como o repertório das manifestações da linguagem corporal que caracterizam os grupos que coabitam a escola. Tal preocupação, no nosso entender, é requisito indispensável para dotar de coerência a função social da instituição educativa comprometida com a formação de cidadãos e cidadãs dispostos a atuar efetiva e criticamente diante da cultura pública à qual estão expostos.

A centralidade das questões culturais traz inevitavelmente à luz a multiplicidade de culturas encontradas hoje no interior de um dado país e que, obviamente, se refletem nas escolas, lançando enormes desafios para suas pedagogias. Essa multiplicidade convive, paradoxalmente, com fortes tendências de homogeneização cultural. Ainda que se venham tornando mais visíveis as manifestações e as expressões culturais de grupos que há pouco tempo permaneciam "invisíveis", ainda se observam propostas curriculares onde predominam formas culturais produzidas e veiculadas prioritariamente pelos setores mais favorecidos da população (SILVA, 2006).

Os movimentos em direção à homogeneização ou em direção à diversificação não se processam sem lutas. As relações entre as distintas identidades culturais, assim como as tentativas, por partes de diferentes grupos, de afirmação e de representação em políticas e práticas sociais, são complexas, tensas, competitivas e imprevisíveis. Esse panorama conflituoso, pleno de avanços e recuos, evidencia-se tanto nos noticiários que veiculam guerras, agressões, perseguições e discriminações, como no sobressaltado cotidiano em que buscamos viver e conviver com a violência, com o fundamentalismo, com a xenofobia, com o ódio e com a exclusão social. "Hoje a necessidade de um reconhecimento e valorização das diversas identidades culturais, de suas particularidades e contribuições específicas à construção do país é cada vez mais afirmada" (CANDAU, 1997, p. 241, citada por MOREIRA, 2002, p. 17). As contradições envolvidas nesse reconhecimento e nessa valorização certamente impõem desafios para a organização e desenvolvimento das ações pedagógicas de qualquer escola.

A pedagogia em contextos culturalmente diversificados se beneficia significativamente quando adota como pano de fundo o conceito de cultura advindo dos 
Estudos Culturais. Sinteticamente, seria possível afirmar que tal cabedal teórico compreende a cultura como processo simbólico, no qual os seres humanos dão sentido às suas produções. Cultura seria toda a produção de significados e, nesse sentido, transformar-se-ia em um verdadeiro campo de lutas para validação (HALL, 2003). Ao enfatizar a diversidade e não a universalidade, os Estudos Culturais reforçam a idéia de humanidade como espécie e propõem que cada grupo ou etnia olhe para os outros como diferentes, nem superiores nem inferiores.

Além disso, não foram poucos os teóricos da educação que, ao longo do século XX, buscaram entender as sutis relações entre aprendizagem e interação social, interação esta que ocorre por meio da linguagem, ou seja, de um dos fundamentos da cultura.

Os argumentos apresentados acima subsidiam a necessidade de realização de estudos que permitam elucidar como as pedagogias vêm tratando as diferenças culturais no interior da escola. Reconhecendo a amplitude do tema, nesta investigação nos debruçamos exclusivamente sobre o tratamento pedagógico que uma escola indígena vem destinando às práticas corporais. Parece óbvio que todos temos um corpo e nos comunicamos por meio dele. Também parece evidente que crianças e jovens em geral se utilizam mais de seus corpos enquanto suporte para a expressão dos seus sentimentos e modos de ver o mundo, bem como com intenções lúdicas, do que os adultos. No entanto, dezenas de atitudes (cotidianas ou não) nas quais os movimentos corporais são acionados, quase sempre como forma de linguagem, deixam de chamar a atenção de pais, educadores e pesquisadores. Ao investigar como a escola aborda a cultura corporal de uma comunidade específica, nos propomos a focar seus gestos como manifestações culturais, dar-lhes esse estatuto, pensar sobre eles, conhecer suas histórias e suas possibilidades expressivas, simbólicas e pedagógicas. Sem dúvida alguma, aqui se configura um campo de investigação muito frutífero para entender as relações entre corpo e movimento, movimento e cultura, cultura e expressão, expressão e educação.

Há um certo consenso de que nas sociedades indígenas o corpo é amplamente utilizado para fins expressivos. A arte indígena é repleta de manifestações de pintura corporal e confecção de objetos ao mesmo tempo artísticos e utilitários ou ainda de uso ritual. Povos indígenas possuem danças e gestos específicos, usam o corpo nos rituais e nas brincadeiras. Porém, os conceitos de corpo e pessoa mudam de um grupo para outro, bem como os usos que fazem de seus corpos. Essa diversidade - tão característica dos povos indígenas - atrai e intriga pesquisadores há gerações.

Em função disso, este estudo buscou verificar como as práticas da cultura corporal Guarani são socializadas no ambiente escolar da Escola Estadual Indígena Kuaray Oêã (Sol Nascente), localizada na aldeia guarani Itaóca, município de Mongaguá, estado de São Paulo. Na localidade residem cerca de 22 famílias, pertencentes a dois subgrupos da etnia Guarani, os Mbya e os Nhandéva, que se autodenominam "Tupi-guarani” ou simplesmente "Tupi".

À época da investigação, entre março e julho de 2007, a instituição era dirigida por um membro da etnia Guarani-Mbya que ocupava o cargo de vice-diretor, mas acumulava funções de secretário, diretor e coordenador pedagógico. As atividades escolares distribuíam-se pelos turnos matutino e vespertino. O período da manhã recebia 25 alunos pertencentes à etnia Guarani-Mbya distribuídos em dois grupos: um composto por crianças menores, com as quais era desenvolvido o currículo correspondente à primeira e segunda séries do ensino fundamental e outro composto pelas crianças mais velhas e jovens, que recebiam "o ensino correspondente à terceira e quarta séries", Neste grupo não havia indivíduos miscigenados, todos pertenciam à etnia Mbya. O turno da tarde apresentava 
organização semelhante, no entanto, todos os seus 12 alunos eram crianças ou adolescentes, filhos de uniões entre índios Nhandéva e brancos, negros ou pardos.

\section{A educação escolar indígena no estado de São Paulo}

O estado de São Paulo possui em seu território aldeias das tribos Guarani Nhandéva, Guarani Mbya, Terena, Kaingang, Krenak e Pankararu, formando um conjunto de aproximadamente 29 aldeias. Em cumprimento à legislação estadual que tem orientado as ações do Núcleo de Educação Indígena (NEI), da Coordenadoria de Ensino do Interior (CEI) e da Coordenadoria de Estudos e Normas Pedagógicas (CENP) da Secretaria de Estado da Educação (SEE) ${ }^{3}$, têm sido implementadas medidas legais para definir as escolas indígenas como escolas diferenciadas, onde o ensino é intercultural e pode ser bilíngüe desde que a comunidade da aldeia assim o decida.

Claro está que a política estadual para povos indígenas, em especial no que respeita à educação escolar, está sendo conduzida a reboque das iniciativas e demandas legais de âmbito federal. Em análise desse processo, Grupioni (2004) evidencia os alcances em termos de educação escolar indígena no Brasil, mas apresenta, também, alguns dos diversos desafios que ainda existem para que esse direito seja exercido pelas diferentes populações. Esmiuçando o Parecer no 14/1999 da Câmara de Educação Básica do Conselho Nacional de Educação, que estabelece as Diretrizes Curriculares Nacionais para a Educação Escolar Indígena, o autor afirma que ele dá origem à Resolução CBE/CNE n ${ }^{\circ}$ 03/1999. Tal resolução impõe, com prazos previstos, que a categoria "escola indígena" seja regulamentada pelos Conselhos Estaduais de Educação, apontando para o rompimento da situação atual dessas escolas como salas de extensão ou escolas rurais.

Khan e Azevedo (2004), na mesma obra, apresentam dados do Censo Escolar 2003, que informam que naquele ano havia no Brasil 2079 escolas em aldeias, com 150 mil estudantes matriculados e 7 mil professores, sendo $85 \%$ deles pertencentes a povos indígenas. E fazem um alerta às autoridades responsáveis pela educação escolar indígena em nosso país: "é preciso dizer que o Estado terá que investir muito em pesquisas lingüísticas e de registro dos conhecimentos tradicionais, pesquisas onde esses conhecimentos dialogam com aqueles tradicionais das escolas, ditos ocidentais". (p. 70) Atentam ainda para a urgência de "conscientização dos órgãos governamentais sobre as necessidades especiais que essa educação exige, principalmente na primeira fase de criação de escolas e de concepção do Projeto Político-pedagógico, para a qual há um demanda urgente por assessorias especializadas" (p. 75).

São os compromissos com estes investimentos, bem como com o atendimento das necessidades apontadas, que os Estados devem assumir para atender as aldeias e as escolas de forma específica, respeitando seus direitos.

Muitos são os desafios enfrentados para a construção de escolas de educação indígena que ofereçam às populações que atendem o uso e acesso à sua língua materna (oral e escrita), à língua portuguesa e/ou às demais línguas que sejam faladas pelo grupo, bem como aos demais conhecimentos ditos tradicionais da escola: matemática, geografia, história, educação física, arte, língua estrangeira. O debate a esse respeito é intenso. Khan e Azevedo (2004) propõem uma modalidade de ensino específica, um "sistema de educação indígena" (p. 78), de âmbito federal, já que há povos que habitam em mais de um município (inviabilizando a municipalização do ensino nas diversas aldeias), ou em mais de um estado, ou mesmo em vários países, como é o caso dos Guarani e outros povos 
indígenas do Brasil. Tal sistema traria mais agilidade no atendimento, na troca de experiências de formação, melhor uso das verbas etc.

\section{Contexto histórico e cultural dos povos Guarani do estado de São Paulo}

A população Guarani do Brasil está presente em 22 áreas indígenas e constitui uma etnia com cerca de 25 mil pessoas ${ }^{4}$. Contém, porém, subgrupos com dialetos e práticas culturais próprias. São eles: Guarani Mbya, Guarani Nhandéva ou Chiripá e Guarani Kaiowá. Em São Paulo atualmente residem em aldeias elementos dos subgrupos Nhandéva (outros nomes: Avakatueté, Chiripá) e Mbya.

As aldeias Guarani do estado de São Paulo encontram-se nas cidades de São Paulo, Avaí, Bertioga, Ubatuba, Miracatu, Mongaguá, Itanhaém, Peruíbe, Iguape, Itariri, Cananéia, Pariquera-açu e Sete Barras. Na aldeia de Itaóca, onde se encontra a Escola Estadual Indígena Kuaray Oêã, localizada no município litorâneo de Mongaguá, residem indígenas das etnias Guarani Mbya e Guarani Nhandéva, estes últimos também denominados, e freqüentemente autodenominados, Tupi-guarani ${ }^{5}$.

Ambos subgrupos reconhecem semelhanças entre si, mas destacam as diferenças que possuem como forma de distinção e afirmação de uma identidade própria. Embora sejam todos da mesma tribo, os subgrupos Mbya e Nhandéva ocuparam a região do litoral paulista, fluminense e capixaba em levas sucessivas, misturando-se nas diversas aldeias litorâneas e naquelas situadas na cidade de São Paulo.

Tanto Ladeira e Azanha (1988) quanto Schaden (1974) basearam-se nos trabalhos de quem consideram o maior estudioso das migrações guarani em direção ao litoral paulista, o antropólogo Curt Nimuendajú, para narrar a trajetória dessa tribo. Por um pequeno trecho da obra de Schaden entendemos um pouco da origem das migrações dos subgrupos Nhandéva e Mbya em direção ao litoral:

A história dos Guarani em território paulista é bastante conhecida, graças aos trabalhos de Nimuendajú e de outros investigadores. Sabe-se que entre eles não há remanescentes dos antigos Tupi da costa, desaparecidos já no período colonial. Ligam-se às correntes migratórias, provenientes do Oeste, que se vêm sucedendo desde o primeiro quartel do século passado. O motivo das jornadas é o yvý opa, o fim do mundo, profetizado pelos chefes religiosos da tribo. (p. 04)

Nimuendajú relata a migração de alguns grupos Guarani já no século XIX: Tañiguá (1820), Oguahuíva (1820), Apapokúva (1870). Desde 1850, forma-se grande concentração em Itararé, ao sul do estado de São Paulo, em terras que pareciam ter sido doadas pelo Barão de Antonina. Em 1912, há uma dispersão de cerca de 500 índios deste aldeamento; alguns foram para Itariri e Bananal, outros para o interior do estado, cidade de Araribá, onde persiste um posto indígena desde o início do século XX, no qual atuou Nimuendajú.

Ladeira e Azanha (1988) complementam:

A partir das primeiras décadas deste século, os núcleos Nhandeva do litoral passam a receber o reforço de outros grupos, também Guarani e classificados na literatura etnográfica como Mbyá. Este grupo, a partir das décadas de 50 e 60 , passa a constituir a população dominante no litoral. (p. 15)

A respeito das migrações Mbya, Schaden (1974) é enfático: 
As migrações mais recentes foram as de algumas levas de Mbüá do leste paraguaio e nordeste argentino que, atravessando o Rio Grande do Sul, Santa Catarina e Paraná, chegaram ao litoral de São Paulo. Tenho notícias de 3 grupos, um vindo por volta de 1924, outro vindo em 1934 e um terceiro, que chegou em 1946, igualmente vindo do Paraguai meridional, do território contíguo à província Argentina de Misiones. (p. 5)

Como suspeitava Schaden, as migrações Mbya em direção ao litoral paulista não pararam. Na segunda metade do século XX novas levas de Guarani-Mbya foram chegando, vindas do Paraguai e da Argentina, ou de territórios brasileiros fronteiriços a esses países, onde há aproximadamente dois séculos existiram os aldeamentos jesuítas conhecidos como Missões. Os Nhandéva parecem ter interrompido suas migrações ao litoral desde o início do século XX.

Sabemos, portanto, que os Nhandéva chegaram ao litoral antes dos Mbya, e num momento histórico em que a atitude de procurar se integrar à cultura cabocla e caiçara representou uma estratégia de sobrevivência. No entanto, o fato de adotarem práticas culturais dos não-índios, e até mesmo de se misturarem com eles, com a permissão de casamentos com elementos de fora da tribo, não significa que houve perda de elementos essenciais da cultura, como a língua e a religião. As posições de Schaden, resultantes de suas pesquisas na década de 1940, refletem uma situação que perdura até a atualidade:

Quem quer que procure conhecer em suas próprias aldeias os índios Guarani da atualidade, não deixa de perceber desde logo que certos domínios de sua cultura se apresentam inteiramente abertos a influências estranhas, ao passo que em outros é extraordinariamente forte o apego aos padrões tradicionais. (p. 11)

Com relação às práticas religiosas, pode-se afirmar que várias aldeias mantêm suas opy - casa de reza - em condições de uso freqüente, com a presença de pajés responsáveis pela realização de rituais da tradição Guarani. Os praticantes da tradicional religião guarani costumam dirigir-se à casa de reza pelo menos uma vez ao final do dia, onde fumam seus cachimbos de tabaco e bebem chimarrão, fazem suas rezas, conversam entre si. Entre os rituais religiosos destaca-se o ñemongaraí, a cerimônia de imposição dos nomes, ou batismo, das novas crianças da aldeia. É uma cerimônia ligada ao calendário religioso e social do ciclo do milho, e ocorre na época da primeira colheita do milho, no verão, em fins de janeiro e começo de fevereiro. O ritual é conduzido pelo pajé da aldeia ou por um pajé convidado, e dura várias horas, começando no início da noite e se alongando pela madrugada. Muitos integrantes de outras aldeias, geralmente parentes, são convidados a participar, podendo comparecer também alguns jurua ${ }^{6}$ considerados amigos de integrantes da aldeia.

Os grupos Mbya que continuam a chegar ao litoral do estado têm algumas condutas diferentes dos Nhandéva, especialmente no que concerne à miscigenação com não-índios; ela pode ocorrer, mas a pessoa deve abandonar a aldeia, ou seja, na aldeia são permitidos apenas os casais endogâmicos. $\mathrm{Na}$ aldeia investigada, os pajés pertencem ao subgrupo Mbya, para o qual o apego às práticas religiosas tradicionais é mais forte. contexto histórico dos últimos quinze anos corrobora atitudes como essa, de afirmação da identidade de povos indígenas e de seu desejo de serem reconhecidos como diferentes e portadores de direitos específicos em função das suas características culturais. Bem diferente era o contexto das migrações dos Nhandéva do século XIX até meados do século 
$\mathrm{XX}$, período no qual a integração à sociedade mais ampla era uma maneira de absorver influências em alguns aspectos de sua cultura, resistir a outros, mas de qualquer modo alcançar maior respeito das comunidades não-índias com as quais necessitavam se relacionar.

Ainda a respeito da afirmação de identidade, pudemos constatar que a gravação em CD-ROM e divulgação de algumas das suas rezas representou ocasião de afirmação da identidade cultural Guarani, especialmente do subgrupo Mbyá. Lançado em 2000 o primeiro CD-ROM reunia integrantes de quatro aldeias Guarani-Mbyá do litoral paulista e fluminense. No texto do encarte que acompanha o compacto, a ênfase está na importância da divulgação da cultura Guarani entre os juruá e entre os próprios Guarani, reafirmando sua ancestralidade, sua riqueza e seu direito de continuar viva. O texto foi extraído de depoimento de Timóteo Verá Popyguá, da aldeia de Morro da Saudade, em Parelheiros, município de São Paulo, e revela o sentimento de fortalecimento dos laços culturais entre as aldeias ocorrido durante os encontros para produção do $\mathrm{CD}-\mathrm{ROM}^{7^{3}}$. O segundo $\mathrm{CD}$ ROM, de 2004, mostra o quanto a experiência anterior frutificou: é um compacto duplo com participação de cerca de "300 crianças e músicos de 10 aldeias guarani e uma aldeia tupi-guarani dos estados de São Paulo e Rio de Janeiro" ".

Na perspectiva deste estudo, a reza, por ser comumente acompanhada de vivências rítmicas é elemento relevante na valorização da cultura corporal indígena. Schaden (1974) nos ajuda a compreender tal patrimônio ao mencionar que a reza (porahêi pra os Nhandéva, poráí para os Mbya), é traço de união entre o mundo dos vivos e o sobrenatural.

O recurso sempre à mão de que dispõe o Guaraní para provocar e ao mesmo tempo dar vazão a suas vivências religiosas é o porahêi ou reza. O porahêi é sempre cantado e requer acompanhamento de mbaraká e takuápú para marcação do ritmo da dança. Canto, dança (djiroký) e som instrumental constituem assim uma unidade (p. 118).

Cada porahêi consiste (...) em texto e melodia, ligados a movimentos rítmicos de dança. Muitos dos textos são incompreensíveis, havendo uma série de notas alongadas e algumas palavras, mais ou menos conexas, referentes à esfera sobrenatural. $\mathrm{O}$ importante não parece ser o sentido das palavras em sua sequiência lógica, mas o seu poder evocativo no domínio das vivências religiosas. Durante o porahêi intensifica-se o sentimento religioso, a ponto mesmo de se produzir estado de êxtase. Alheios a tudo que se passa em torno deles, os participantes experimentam profundo arrebatamento, ficando, não raro, com o rosto transfigurado, e chegando a chorar de emoção (p. 119).

O porahêi individual, presente dos deuses ou espíritos, como o conhecem os Nhandeva e Mbüá, é transmitido através do sonho. (...) As rezas que constituem parte integrante das festas religiosas dirigidas pelos sacerdotes são mais ou menos conhecidas por todo grupo. Quanto às individuais, são recebidas às vezes já na puberdade, outras na idade madura (p. 120).

\section{A educação entre os Guarani}

A forte presença da reza (canto, dança e som instrumental) na cultura guarani, inclusive como um dos aspectos fundamentais na reafirmação da identidade, chamam nossa atenção para as questões do corpo, da educação do corpo, da noção de pessoa Guarani. 
A investigação empreendida por Moura (2005) acerca da iniciação ancestral vivida pelas crianças guarani Mbya, destaca as questões do corpo e apresenta a "pessoa Guarani" como um "corpo sonoro", como ser que é som, "palavra-alma". O som, ritmo, a harmonia de cantos e danças (rituais) são o que materializam as relações orgânicas entre uma determinada cosmologia e uma determinada sociologia. Na ótica da autora, para esse povo, "a humanidade seria menos o nome de uma substância e muito mais um tipo de relação" (p. 24).

Sobre os cantos e danças rituais e seu papel nessa relação que constitui o ser, ou seja, a pessoa Guarani, afirma:

A transmissão dos mitos pela dança e pelo canto não refere nem nomeia coisas visíveis, como a linguagem verbal faz, mas aponta uma força para o não verbalizável; atravessa certas redes defensivas que a consciência e a linguagem centralizada opõem à sua ação e toca pontos de ligação efetivos do mental e do corporal, do intelectual e do afetivo, isto é, da corporeidade (p. 26) (...) podemos observar que o papel crucial do ritmo, na qualidade de palavra-alma, não está limitado à auto-organização e à auto-expressão, mas se estende à percepção sensorial, à comunicação e ao engendramento, tanto da pessoa, quanto dos deuses no cosmos. (p. 33)

A educação das crianças, que Moura denomina "iniciação ancestral", ocorre dentro dessa concepção de pessoa, e os ritos vividos no cotidiano das aldeias é que formam cada um dos Guarani.

Schaden (1974) também se dedica a compreender o processo educacional e a concepção de pessoa para os guarani. Em sua obra, o autor está interessado nos aspectos fundamentais da cultura guarani, aqueles que, mesmo diante do atual processo de aculturação atravessado por esse povo, persistem. Trata-se aqui da autonomia das crianças, verificada nas diversas aldeias que visitou:

Tal característica é o respeito pela personalidade humana e a noção de que esta se desenvolve livre e independente em cada indivíduo, sem que haja possibilidade de se intervir de maneira decisiva no processo. No que respeita ao desenvolvimento psíquico e moral da pessoa, o Guarani descrê inteiramente da conveniência e da eficácia de métodos educativos, a não ser a título excepcional ou por via mágica. (p. 59)

$\mathrm{O}$ extraordinário respeito à personalidade e à vontade individual, desde a mais tenra infância, torna praticamente impossível o processo educativo no sentido da repressão. As tendências da criança nada mais são, na opinião do Guarani, do que manifestações de sua natureza inata (p. 60).

A descrença no processo educacional para os Guarani é coerente com a noção de pessoa, que por sua vez articula-se à concepção religiosa de alma, ou da individualidade psíquica e moral, que, "já nasce pronta ou, pelo menos, com determinadas qualidades virtuais, por assim dizer embrionárias" (p. 61). Os Guarani acreditam que pouco pode ser feito para mudar as potencialidades dos indivíduos, dado que já trazem em sua alma determinadas propensões. Por isso o batismo é uma cerimônia tão importante. Nele, o pajé nomeia cada uma das novas crianças da aldeia após receber em sonho os nomes apropriados, indicando suas tendências e até mesmo seu destino.

Com relação ao aspecto educacional do ritual de iniciação dos meninos Mbya, que envolve a perfuração do lábio inferior onde se encaixa um tembeta, Schaden (1974) relata: 
Condição essencial é que o menino tenha passado previamente por um período de aprendizagem, sob a orientação do pai ou de alguma pessoa encarregada, em que se lhe tenham ensinado as técnicas de trançar e outras habilidades - para que não venha a tornar-se preguiçoso (...). No Rio Branco, o índio Karaí ou Marcelino Rosa me explicou que os iniciandos recebem uma série de recomendações ou conselhos (a que chamava 'educação'). São mais ou menos os seguintes: 'trabalhar bastante, plantar bem, não fazer mal a ninguém, não ofender a família dos outros, não maltratar a ninguém, comportar-se bem nas viagens (isto é, não beber muita pinga), fazer os trabalhos de roça bem feitos, não maltratar a mulher quando casar (p. 89).

\section{Percurso metodológico da investigação}

A metodologia adotada baseou-se no estudo de caso de tipo etnográfico (ANDRÉ, 1995 e GEERTZ, 1989). Como instrumentos para coleta de dados foram empregadas observações participantes das atividades didáticas e das práticas corporais presente na comunidade, sendo devidamente registradas em diário de campo; entrevistas gravadas com os dois professores responsáveis pelas turmas e com o gestor da escola; registros fotográficos e conversas informais com outras pessoas da aldeia e com os trabalhadores da escola.

Por vezes o contexto da observação das atividades didáticas se modificou. Houve uma saída para coleta de lixo pelo núcleo Mbya, e a visita de estudantes de ensino médio de Santos, que, entre outros espaços, conheceram a sala de aula. Foram observados ainda os eventos do recreio, que ocorriam no pátio coberto da escola, também utilizado como refeitório, assim como as áreas próximas que as crianças percorriam no tempo livre de que dispunham; crianças brincando nas áreas do entorno da escola ou circulando pelas trilhas que passam por ela e cenas de trabalho coletivo no núcleo Mbya da aldeia.

De posse de todo o material - diário de campo e transcrição das entrevistas - os dados foram analisados, categorizados e submetidos à descrição crítica por meio de um confronto com a teorização cultural, com os estudos da educação indígena ${ }^{9}$ e com o trabalho antropológico de Mauss (1974).

\subsection{Formas de transmissão do patrimônio cultural guarani}

Os dados obtidos indicam que na comunidade investigada algumas pessoas assumem um papel fundamental na transmissão da cultura indígena. Em muitos momentos, por exemplo, é o próprio gestor da escola que se responsabiliza pela perpetuação de práticas e rituais característicos. Na cultura Guarani, conforme explicitado anteriormente, o nome de uma criança é recebido em sonho pelo pajé, que realiza o batismo, e possui forte influência na educação que será dada a esta criança, pois o nome revela tendências que devem ser estimuladas em sua formação. No caso do nosso informante, seu nome guarani, apresentado orgulhosamente na entrevista, significa, segundo Ladeira (1992), "aquele que melhor distribui as coisas" (p. 127).

Desde muito jovem, ele se dedica a contar histórias para as crianças e até recentemente, assumia a coordenação do grupo de canto e dança do núcleo Mbya da aldeia. Sua formação docente, adquirida mediante convênio entre a Secretaria Estadual de Educação de São Paulo e a Faculdade de Educação da USP e sua militância a favor da instalação de uma escola pública na localidade que atendesse as demandas da aldeia, 
permitiu sua escolha pela comunidade para ser o "professor da aldeia". Seu envolvimento com as tradições indígenas pôde ser verificado na temática focada pela pesquisa que desenvolveu para o Trabalho de Conclusão do Curso de Magistério Superior Indígena, onde buscou investigar os instrumentos musicais da tradição Guarani.

Sua fala revelou a existência de situações de valorização da transmissão vertical dos conhecimentos - dos mais velhos para os mais novos - na forma de relatos orais dos mitos e lendas do povo Guarani: "Os mais velhos falam, ou cantam, e as crianças ouvem sentadas". Alguns tabus relativos ao nascimento dos bebês e à menstruação ficam sob a responsabilidade das famílias, que conversam com seus filhos para que aprendam o que não podem comer ou as atividades que não devem realizar nestes períodos. Conforme notamos, a escola respeita esses comportamentos provenientes da cultura Guarani, sem porém destinar sobre eles qualquer reflexão pedagógica.

Os comportamentos em questão dizem respeito ao que Schaden (1974) chama de estados ou situações de crise na vida guarani: o nascimento de uma criança e a menstruação das jovens, por exemplo, são momentos delicados e caso haja desrespeito aos procedimentos recomendados pela cultura, os transgressores poderão adoecer. Por essa razão, durante o período menstrual, as jovens devem permanecer em casa, mesmo que isso implique em ausentar-se da escola. Ao referir-se às situações de crise na vida guarani, o autor menciona o nascimento como a mais corriqueira, sendo forte a presença da couvade, ou seja, o "resguardo" masculino: "Trata-se principalmente de permanência na habitação, ligada à proibição de atividades e a restrições alimentares, estas últimas, ao que pude saber, mais rigorosas entre os Mbyá, que em geral dispensam maior atenção aos problemas de dieta” (p. 84).

Não trabalhar, não andar no mato, não comer certas comidas, especialmente o tatu, abstinência sexual, não mexer em aço, dormir pouco, tudo para evitar o odjépotá, para não ficar $a k u$. Odjépotá na cultura guarani representa "o bicho (que) se mistura com a gente e a gente fica vivendo com o bicho toda vida". (p. 84)

Dentre as ocasiões específicas para a transmissão cultural, as reuniões semanais da comunidade constituem-se em ocasiões relevantes, nas quais diversos assuntos da aldeia são debatidos: trabalhos coletivos, decisões políticas, tomada de atitudes, problemas de indisciplina na escola etc. Crianças a partir de dez anos, aproximadamente, podem participar. Para elas, as reuniões são momentos importantes de aprendizagem quanto ao respeito à palavra dos mais velhos, já que ser um bom orador, ou seja, possuir as nhe e porã, as palavras bonitas e adequadas para o momento, para esclarecer e convencer as pessoas, é uma habilidade muito apreciada entre os Guarani. Segundo Ladeira (1992), em uma "sociedade oral por excelência (...) o conhecimento das "belas palavras", base dos ensinamentos, é o atributo mais desejado. Aprimorar-se é aperfeiçoar seu discurso oral, pela penetração que este pode alcançar no seio da comunidade". (p. 66)

As danças e cantos da tradição são também formas de transmissão da cultura, mas não estão inseridas no cotidiano da escola. Entre os Mbya, elas ocorrem como reza, na casa do pajé ou em rituais da religião Guarani, aos quais não tivemos acesso.

Entre os Nhandéva, nota-se a preocupação entre as lideranças de inserir o canto e a dança no currículo da escola, com horário previsto dentro das atividades pedagógicas, inclusive porque este subgrupo não possui uma casa de reza e pajé próprios. Um dos professores entrevistados, que anteriormente vivia na aldeia Piaçaguera, afirmou: "Que nem, lá na outra aldeia tinha reza. Né? Que era com o... com o Guaíra e tudo. Ele que... fazia a reza de noite lá... E todo mundo ia, adulto, criança”.

Comparando uma aldeia com a outra, o professor evidenciou que as lideranças de Itaóca vêem a possibilidade de oferecer na escola ensinamentos da tradição que a própria comunidade está perdendo. Não só conteúdos, como a língua guarani em seu dialeto 
Nhandéva (ao qual todos se referem como língua Tupi-guarani), como também as formas tradicionais do canto e da dança, mesmo que distanciados de seu conteúdo religioso.

O depoimento do cacique Nhandéva demonstrou preocupação com o fato de as crianças já não conversarem em "Tupi-guarani”" com os pais, que muitas vezes não são indígenas (a mestiçagem é clara entre as famílias Nhandéva); por isso, chegou a mencionar que talvez a aldeia pudesse ter uma espécie de "Mobral de Tupi", para ensinar aos adultos a falar, ler e escrever nesse dialeto, pois, segundo sua compreensão "não adianta aprender na escola e na casa não falar".

Chamou-nos a atenção o fato de as lideranças Mbya parecerem menos preocupadas com estes aspectos; percebemos que os cantos e danças entre eles são ainda reza, ocorrem num contexto religioso, e o fato de essas práticas não ocorrerem no cotidiano da escola não lhes trazia qualquer incômodo. Tanto o gestor como o professor Mbya mostraram-se mais preocupados com que a escola prepare suas crianças e jovens para o "mundo lá fora", para o "impacto" que recebem no contato com a cultura não indígena quando passam a conviver mais com a sociedade envolvente e vão estudar nas escolas dos jurua.

\subsection{A gestualidade na escola indígena}

Sob influência da leitura do texto clássico do antropólogo Marcel Mauss (1974), fomos instigados a observar mais detidamente a gestualidade característica da comunidade investigada. Empregando a mesma técnica empregada pelo reconhecido pesquisador, recorremos a uma descrição detalhada dos eventos presenciados e buscamos atribuir-lhes sentido. Entretanto, o excesso de dados disponíveis obrigou-nos à divisão desta categoria conforme o contexto no qual os gestos foram identificados.

\section{a) Posturas docentes na relação com às crianças e adolescentes e suas implicações disciplinares}

Entre os professores Mbya ${ }^{10}$, verificamos que em geral trabalham de pé, sentam-se pouco e sempre à sua mesa; raramente sentam-se com uma criança, embora circulem muito e atendam as crianças nas carteiras. Jamais gritam. Advertem as crianças falando baixo e com semblante sério. Sorriem com freqüência. Fazem perguntas. Cantam com as crianças. Os "sermões" são raros. Têm total controle sobre a disciplina da turma e poucas vezes necessitam chamar a atenção das crianças, sendo sempre atendidos em suas orientações. São mais pacientes com as crianças novatas na escola. Pudemos observar a "iniciação" de uma dessas crianças que, por meio das interações com o professor, aos poucos, adaptou seu repertório gestual às exigências escolares e sem qualquer dificuldade desenvolveu as atitudes esperadas (permanecer várias horas sentado, escrever, pintar, apontar, apagar etc.).

$\mathrm{Na}$ relação com os pequeninos, que perambulam com muita liberdade pela sala de aula, agem da mesma maneira e não identificamos situações de indisciplina devido à presença deles. Quando surge qualquer sinal de alteração, os professores agem firme e serenamente, e são prontamente atendidos.

Exercendo sua função estritamente docente, a de ensinar, os professores perguntam, escrevem e desenham na lousa, explicam, circulam pelas carteiras, fazem intervenções individuais e coletivas, solicitam a leitura, eles próprios lêem devagar, passam a lição na lousa e no caderno, propõem exercícios, apagam, corrigem, pesquisam no dicionário e fazem registros.

Parece-nos impossível abordarmos o assunto das práticas corporais desse grupo sem efetuarmos uma comparação da situação acima com as práticas verificadas entre os 
"Nhandeva". O professor passa boa parte da aula sentado, ou à sua mesa, ou junto a alunos, às vezes sentando-os no seu colo. Pega na mão dos menos hábeis com o lápis para auxiliálos. Beija e abraça os pequenos. Sorri. Ele vai mudando de lugar e muitas vezes é cercado pelas crianças, sentado à sua mesa ou junto a algum aluno. Irrita-se com freqüência e faz ameaças de mandar bilhete ou conversar com os pais ou com o diretor, chegando a gritar algumas vezes. Faz repetidas advertências de que "precisa sentar direito para escrever!".

Apesar de ser uma turma menor e predominantemente composta por crianças maiores (apenas uma criança abaixo da idade escolar participava das atividades na sala de aula), as situações de indisciplina observadas foram numerosas e constantes. Para ensinar, o professor usa a lousa com muita frequiência e escreve textos seguidos de exercícios que são copiados pelos alunos. Lê com rapidez. Faz mais atendimentos individuais que coletivos, tanto para explicar como para corrigir. Nestas aulas, o repertório de gestos ligados às intervenções pedagógicas é mais restrito do que o de gestos ligados à intervenção disciplinar ${ }^{11}$, ao contrário do que ocorre entre os Mbya.

Atribuímos as diferenças constatadas entre as posturas docentes a um conjunto de fatores extremamente imbricados. As atitudes do professor Mbya dão a ele a autoridade que a comunidade espera que ele tenha junto às crianças, enquanto líder e possuidor das "belas palavras". Ele mantém uma distância corporal sem perder o bom humor, o interesse e a preocupação com as tarefas que as crianças estão realizando. Propõe diversas atividades pedagógicas dedicadas à leitura, escrita e cálculo, envolvendo boa parte da atenção das crianças, principalmente dos adolescentes, quase todos já alfabetizados. Como vimos, a comunidade espera que a escola os prepare para o impacto que sofrem no contato cotidiano que certamente virão a ter mais intensamente com os juruá, com seus hábitos e valores. Para esse contato, o domínio da língua portuguesa e das operações com números é fundamental. Entendemos que uma parte da explicação sobre o "sucesso" do professor Mbya, em comparação com seu colega Nhandeva, está na relação com a comunidade, que dá amparo a suas atitudes, e ao mesmo tempo é atendida em seus anseios quanto à escolarização de suas crianças $^{12}$. Afirmamos anteriormente que algumas posturas historicamente exigidas pela tradição escolar, como ficar sentado e ouvir, são posturas ensinadas e estimuladas pela educação guarani. Além disso, o gestor da escola, da mesma etnia, faz presença constante dentro e fora da sala de aula no horário dessa turma, o que amplia o poder de observação e coerção dos adultos sobre as crianças.

Entre os Nhandéva, a relação escola-comunidade aparenta uma certa tensão, o que dificulta ainda mais a atuação do professor. Em conversas informais com algumas pessoas desta etnia, constatamos que a oferta de educação intercultural e bilíngüe na escola da aldeia não representa desejo de toda comunidade Nhandéva. Duas famílias, por exemplo, não matricularam seus filhos na aldeia, mas sim numa escola municipal na área urbana do município. Além disso, o fato do professor não possuir formação em magistério foi mencionado mais de uma vez pelos adultos como um problema, ou seja, o descontrole disciplinar que ocorre em sua turma poderia advir da falta de qualificação profissional. Neste sentido, inferimos que, provavelmente, o referido professor encontra exclusivamente na própria experiência enquanto aluno os subsídios para a sua atuação docente. Daí ser possível explicar a persistência de posturas de controle e coerção. Colabora ainda para agravar a situação, a informação de que o cacique, ao oferecer um cargo de professor para uma pessoa de outra aldeia e sem formação adequada, teria impedido que os Nhandéva estudassem fora da aldeia, "já que todos falam português", com direito ao transporte escolar gratuito e a aulas com um "professor formado".

A ausência do gestor da escola nos horários de aula dos Nhandéva, por certo, promove o aumento de situações de indisciplina. Dado que nesta turma há vários alunos 
com experiências anteriores de escolarização fora da aldeia, percebem-se condutas características da cultura escolar e que prejudicam o andamento das atividades de ensino tais como "enrolar" (fingir que está "fazendo a lição", mas...), desafiar a autoridade do professor, dedurar os colegas, mostrar o defeito do outro, comparar um aluno com outro, ter medo de ir para a sala do diretor (quando ele está) etc.

Por fim, constatamos também que os conflitos ocorridos entre os alunos muitas vezes refletem, na verdade, contendas familiares exteriores à escola e representam situações de difícil administração para o professor.

Uma análise mais detalhada das reações provocadas pela presença de crianças pequenas na sala de aula, bem exemplifica as diferenças nas posturas docentes. Em termos gestuais, as atitudes das crianças pequenas de ambas as etnias são semelhantes: circulam pela sala, explorando amplamente o ambiente e os recursos didáticos à disposição, entram e saem da sala muitas vezes, fazem evoluções pelo ambiente, saltando, pulando, imitando animais, interagem com as crianças mais velhas, imitam posturas de aprendizagem escolar como escrever, apagar, apontar, pintar, ler etc.

Comparando as duas etnias, percebe-se que, embora entre os Mbya a presença de pequenos seja maior em número e haja maior variedade de gestos, ela não gera indisciplina nem irritabilidade no professor, ao contrário do que acontece na turma dos Nhandéva, na qual a presença de apenas uma criança provoca constantes reações de desassossego no professor $^{13}$.

Considerando o atual contexto democrático e diversificado da escola contemporânea e seu compromisso com uma formação voltada para a participação crítica na vida pública, teóricos da educação multicultural do porte de Kincheloe e Steinberg (1999), Moreira e Candau (2003) e Silva (2006) coincidem ao afirmar a necessidade do desenvolvimento de pedagogias que promovam a articulação entre cultura local, regional ou tradicional, com a cultura escolar.

Verificamos que tal intenção é manifestada pelos sujeitos envolvidos na educação escolar da aldeia, já que tanto as lideranças Mbya quanto a Nhandéva reputam à escola grande importância na manutenção da cultura indígena e, simultaneamente, no acesso das crianças e jovens à cultura da sociedade mais ampla. Contudo, a análise das observações indica que a escola tem dispensando pouca atenção à cultura guarani, chegando, na nossa visão, a contribuir para sua fragmentação, tendo em vista que as crianças pertencentes às diferentes etnias têm ao seu dispor condições e currículos diferenciados.

Essas diferenças, conforme se notou, só fazem reforçar comportamentos discriminatórios. Em diálogos com as crianças Nhandéva, ouvimos expressões como: "foram os índios!", referindo-se a crianças Mbya; ou: "Olha os índios!", quando uma criança apontava uma família Mbya que chegava da cidade com cestos de carregar. Uma delas, ao ser questionada: "E você, não é índio?", respondeu: "Não, sou Tupi!". E ficamos pensando: e o que ela pensa que é ser Tupi?

Por sua vez, o professor Mbya mostrou-se resistente com relação aos comportamentos das crianças Nhandéva que, em sua opinião, refletem a maneira segundo ele inadequada - com que este subgrupo educa seus filhos. Assim, talvez possamos deduzir que famílias Mbya instruam seus filhos a não interagirem com os Nhandéva e vice-versa.

Quando o professor Nhandéva fala das suas intenções de inserir os ensaios de um grupo de canto e dança de sua etnia nas atividades da escola, revela preocupação com a manutenção e principalmente preservação, entre as crianças, da "sua cultura". Suas intenções, conforme notamos, não abrangiam a valorização dessa experiência cultural por meio de atividades pedagógicas como registrar as canções, ouvir/ler outras canções, 
inclusive de outras etnias, conhecer as histórias de seu povo ligadas aos conteúdos das danças e das canções etc. Tais ações didáticas poderiam, segundo defende a pedagogia multicultural, constituírem-se em momentos preciosos para um entendimento crítico do próprio repertório e o acesso ao patrimônio dos outros grupos.

No entanto, os dados coletados durante as atividades e posicionamentos em sala de aula revelam um grande compromisso com a cultura não-indígena. A partir daí, podemos inferir que a imersão e imposição da cultura pertencente à sociedade mais ampla, quase sempre reforçada pela escola, contribui para a adoção de posturas de resistência, por parte dos alunos, manifestada através da indisciplina constante.

\section{b) Técnicas corporais da tradição guarani}

$\mathrm{Na}$ escola verificamos alguns gestos que julgamos serem específicos da cultura guarani. $\mathrm{O}$ andar ocorre com freqüência acompanhado do arrastar dos pés, de preferência descalços, mesmo nos dias muito frios. Observamos também diferentes posições para comer, abrangendo o uso das mãos que, delicadamente, selecionam os alimentos no prato ou arrancam cuidadosamente pedacinhos de um txipa ${ }^{14}$.

Foram detectados ainda gestos como cuspir (na sala de aula este gesto apareceu pouquíssimas vezes, embora seja um gesto muito comum entre os Guarani, pois é uma decorrência do ato de fumar tabaco, freqüente mesmo em crianças maiores e adolescentes); assobiar; catar piolho (atitude freqüente tanto em sala de aula como fora dela).

Com relação ao canto, julgamos importante analisar sua presença, haja vista sua frequiência cotidiana em ambas as turmas em todas as oportunidades de observação. Nas entrevistas com o professor Mbya, cantar aparece como uma atividade da escola, vinculada à cultura corporal dos Guarani, fazendo parte das tradições deste povo. Às vezes as canções entoadas foram aprendidas no ambiente extra-escolar, outras (mais freqüentes) são ensinadas pelos professores, a maioria em português e uma delas, em português, espanhol e guarani. Em outras situações foram entoadas canções da cultura popular de massa, que estão nas rádios e nos programas de televisão ${ }^{15}$. A relevância dessa prática cultural para o povo guarani pode ser conferida em dois trechos dos textos que acompanham os CDROMs do Projeto Memória Viva Guarani (2004), de um dos quais participou o gestor da escola, que à época coordenava o grupo Teko Yvy'a Pyau, composto por jovens e crianças de Itaóca:

Através do canto e da palavra o Guarani se comunica com os Deuses. O canto infantil possui força religiosa, pois as almas das crianças são puras. $\mathrm{O}$ canto tem o poder de curar as pessoas e fortalecer a vida comunitária (p. 01).

Tudo tem um significado para o guarani. Por exemplo, o cântico da criança. Amanhecendo o dia, todas as crianças cantavam esses cânticos tradicionais que estão no $\mathrm{CD}$. Os mais velhos ensinavam as crianças a cantar e explicavam qual é a importância, qual o significado daquele cântico (p. 03).

O sentar, guapy, é uma atitude freqüente entre os Guarani, que utilizam, entre outros, um banquinho de confecção artesanal. Quando chegamos às suas casas, oferecem um banco ou cadeira e dizem "E-guapy!", "sente-se". Schaden (1974, p. 84) faz referência a esse objeto e sua importância nos rituais de iniciação masculina. 
Em ambas as etnias, verificamos variadas maneiras de sentar nas cadeiras da sala de aula: ajoelhado, agachado, de pernas cruzadas, as duas pernas para o mesmo lado, uma para cada lado, penduradas etc. De maneira geral, as crianças Mbya suportam melhor essa atitude dos que os Nhandéva. Uma das explicações para isso talvez resida no fato de que entre os Mbya a força da tradição é maior, como se percebe na leitura das palavras de um importante líder Guarani, um venerável ancião que teve suas palavras gravadas no CDROM Ñande Arandu Pyguá (2004). Numa longa fala, o Xeram oi (literalmente: meu avô, expressão utilizada para se referir ao pajé) João Silva Verá Mir i afirma a necessidade de que as crianças sentem e escutem os ensinamentos: "Deus ensinou a fazer as brincadeiras infantis. E as crianças se colocavam uma ao lado da outra, sentadas, para receber os ensinamentos. Andando de um lado para o outro, em frente às crianças, um velho sábio ensinava as crianças a cantar e a brincar".

Fora da escola, foram verificadas determinadas práticas, principalmente entre adultos em situações de trabalho. Carregam as compras e outros objetos em sacolas e mochilas; as mulheres usam um cesto com tira na cabeça, de confecção indígena, para carregar plantas e outros produtos que são vendidos nas feiras da região. Schaden (1974) se refere a este cesto quando aborda a divisão sexual do trabalho: “(...) dir-se-ia que a mulher Guarani sem a sua cesta-de-carregar é comparável a um soldado sem fuzil. E é um particular importante de sua dependência com relação ao marido, uma vez que a técnica de trançar faz parte da cultura masculina". (p. 76)

Carrinhos de mão são amplamente utilizados para construções e desconstruções, para movimentar terra, areia, pedras, transportar palmito etc. Quanto à locomoção, foram observadas situações a pé (o mais freqüente), de bicicleta (apenas rapazes e homens, nenhuma mulher foi vista se locomovendo de bicicleta, apenas uma menina Nhandéva, brincando), carona com carros oficiais ou de visitantes e automóvel (duas famílias Nhandéva). Outra atividade que pudemos observar foi o transporte de palmito, extraído da reserva por rapazes Nhandéva, que usavam facão e galochas. Um deles é aluno da escola e faltou às aulas para "tirar palmito".

Com relação à confecção e venda de artesanato, observamos duas artesãs Nhandéva trabalhando com o cipó embé para produzir fios que serão trançados e adornados para produzir cestinhos, arcos, flechas, chaveiros e suporte para canetas.

Durante a observação da construção da casa de reza (opy), foi feita uma única observação, quando cerca de doze homens trabalhavam na sua cobertura, no núcleo Mbya da aldeia. Alguns carregavam feixes de sapé morro acima, outros (sentados em vigas ou banquinhos) cortavam as raízes de feixes de sapé com facões, outros (igualmente sentados), organizavam novos feixes, outros estavam sobre o telhado arrumando os feixes. No interior, dois homens, inclusive o cacique, trabalhavam na estrutura do telhado, apoiados em escadas. Conversavam pouco e estavam muito concentrados em seu trabalho.

No mesmo dia em que os homens cobriam a opy, acontecia uma limpeza coletiva de terreno já utilizado anteriormente para plantio, agora para os plantios da primavera; era um trabalho feito predominantemente por mulheres jovens ou ainda adolescentes, que usavam enxadas, pás e carrinhos de mão. As mulheres mais velhas não participavam deste trabalho. Havia várias delas na aldeia, junto aos diversos foguinhos acesos junto a algumas casas, ou debaixo de coberturas que protegiam áreas onde faziam comidas. Uma das anciãs tentou conversar em português; falamos um pouquinho e ela logo se afastou ${ }^{16}$. Algumas crianças ajudavam as mulheres, um garoto ajudava os homens. Era uma manhã de sol, depois de vários dias frios, chuvosos e de muita ventania. Havia muitas roupas, principalmente de crianças, penduradas em cordas entre as casas, a fim de aproveitar ao máximo o calor e a luz solar. Uma explosão luminosa de cores. Várias mulheres lavavam 
roupa nos tanques coletivos instalados junto aos banheiros. As mulheres conversavam animadamente enquanto trabalhavam, sempre em tom baixo. Algumas interrompiam o trabalho para atender suas crianças. Nenhum conflito, apenas risos, conversas, circulação de pessoas, crianças brincando ao sol, todos em franca atividade sob a luz de Kuaray.

Durante a leitura do registro dessa cena, recordamos das referências de Moura (2005) e Ladeira (2001) ao calendário guarani, que se divide basicamente em duas estações, uma quente e chuvosa, outra fria e seca. No dia em questão, via-se o prenúncio de Ara Pyau, o verão, os "tempos novos", a época quente do ano, com tempestades seguidas de sol. Ambas chamam a atenção para a influência do ambiente sobre o comportamento das pessoas. Em Ara Yma - tempo frio, tempo ou ano velho - há um recolhimento das pessoas, que então se dedicam mais ao artesanato, construção, conserto, mas com poucas atividades agrícolas. A proximidade com Ara Pyau promove o desenvolvimento de várias atividades ao ar livre, ligadas aos novos plantios. Tanto as atividades de recolhimento como as de expansão são acompanhados de práticas rituais importantes, como o batismo de sementes e de colheitas, o ritual de corte da erva-mate, o nhemongaraí (atribuição de nomes-almas às crianças), entre outros. Sobre o papel que as atividades agrícolas cumprem na sociedade guarani, Ladeira (2001) explica:

\begin{abstract}
Nhanhoty (vamos plantar). Com esta expressão, os índios Guarani referem-se ao ato coletivo de reproduzir os ciclos anuais da vida social, do trabalho, da organização dos espaços na aldeia e da permanência da família no lugar. Se a prática sistemática da agricultura não é a única condição definidora da identidade Guarani, ela é o eixo estruturante da sociedade e envolve outras esferas da vida coletiva, sociais, simbólicas e rituais. (p. 201)
\end{abstract}

\title{
c) As brincadeiras infantis da cultura guarani
}

Foram significativas, tanto a quantidade como a variedade de brincadeiras observadas na sala de aula, nos espaços externos da escola e demais espaços visitados na aldeia. Todas elas são brincadeiras que também fazem parte da cultura infantil de crianças não indígenas, e as especificidades encontradas dizem respeito ao uso de materiais locais. Cabe destacar ainda o fato de existir na escola, principalmente no pátio coberto, um ambiente que as crianças não encontram em nenhum outro espaço da aldeia: um piso cuja superfície é recoberta de cimento liso e escorregadio. Protegidos do sol ou da chuva, todas as crianças da aldeia usufruem deste espaço sozinhas (raramente) ou acompanhadas de outras crianças, ou de pessoas mais velhas. As crianças circulam livremente pela aldeia, reúnem-se em grupos endoétnicos, e muitas vezes podem ser vistas brincando no pátio da escola. Nesse espaço, conforme observado, apreciam brincar de escorregar de diversos modos, inclusive uns puxando os outros. Jogam bolinha-de-gude, futebol, fazem acrobacias, correm, dançam, rolam etc.

Outro espaço apreciado por elas é o entorno da escola, no qual, com freqüência, são depositados materiais trazidos sob encomenda, geralmente para construção. Assim, areia e pedregulho são matéria-prima para infinitas brincadeiras entre as crianças de diversas idades e de ambas as etnias.

A livre manipulação de objetos para fins lúdicos foi amplamente observada em ambas as etnias, dentro e fora da sala de aula. Jogos eletrônicos foram vistos uma única vez, uma criança Nhandéva brincava com um mini-game enquanto esperava a van da prefeitura vir buscá-la para levar à escola fora da aldeia. 
No núcleo Mbya da aldeia, observado em poucas e efêmeras visitas, verificamos brincadeiras semelhantes às observadas na escola, e outras nas quais pequenos grupos, geralmente divididos por gênero, brincavam com os elementos disponíveis no ambiente: pauzinhos, terra, potes de plástico, folhas de palmeira, pedaços de cana etc. Por vezes pudemos observar duas, às vezes três crianças pequenas que brincavam alegremente com um triciclo de plástico, aproveitando as ladeiras que se formam entre uma casa e outra.

Em algumas casas Nhandéva foram vistas crianças brincando em balanços sob árvores, imitando artistas da televisão, escorregando com papelão pelos barrancos e pulando corda. Andar de bicicleta de forma lúdica é atividade pouco comum, sendo registrada seu uso por mais de uma vez, mas sempre e apenas entre crianças de uma mesma família Nhandéva.

\section{Considerações}

Segundo Neira e Nunes (2006), quando se visa formar para a participação crítica numa sociedade democrática, o projeto escolar deverá potencializar a interpretação, análise, compreensão e ampliação do patrimônio da cultura corporal disponível na comunidade escolar. Aqui se explicita o vínculo a uma concepção de educação escolar indígena ou não indígena - que acolhe a cultura corporal patrimonial como campo de conhecimento de fundamental importância para a valorização da identidade cultural e compreensão sócio-histórica do grupo.

Nessa perspectiva, a escola indígena assume um papel relevante na valorização da identidade cultural dada sua condição de instituição capaz de combater as dificuldades que a comunidade enfrenta para preservar seu patrimônio em função da mestiçagem, avalanche dos valores presentes da sociedade mais ampla, hábitos e atitudes urbanos e à fragmentação da comunidade que, conforme os dados indicam, encontra-se dividida em dois núcleos distintos e de difícil conciliação. Afinal, as práticas sociais observadas permitiram-nos constatar posicionamentos segregacionistas que acontecem devido a preconceitos e posturas monoculturais.

$\mathrm{Na}$ instituição investigada, verificamos pouca preocupação por parte dos profissionais da educação com a inserção do patrimônio da cultura corporal indígena no currículo da escola, embora façam parte do cotidiano da aldeia e tenham no gestor escolar um elemento ativo na sua divulgação. No entanto, quando presenciadas nas dependências escolares, ocorrem exclusivamente na informalidade, a despeito das intenções de ambas etnias, expressas nas entrevistas, nos documentos oficiais da escola e no registro de diálogos com lideranças ${ }^{17}$.

Reforçando essa posição, a investigação desenvolvida constatou que, durante sua ação pedagógica, os profissionais da escola adotam posturas que condizem com a tradição corporal da cultura escolar hegemônica apesar do seu pertencimento étnico. Tal constatação nos permite inferir que se o que se pretende é a educação intercultural (Diretrizes Curriculares Nacionais para a Educação Escolar Indígena), o diálogo entre as práticas pedagógicas da cultura guarani e as práticas pedagógicas escolares deveria ser estimulado. Afinal, por se tratar de um espaço fronteiriço (TASSINARI, 2001), o intercâmbio cultural no qual a relação escola-comunidade deveria pautar-se poderia abranger as trocas das tradições pedagógicas guarani e escolar e não limitar-se às interações entre os diferentes sujeitos.

Essas descobertas colocam em xeque a questão da identidade indígena, pois, conforme alerta Pereira (2004), por não abordar séria e respeitosamente o patrimônio cultural corporal indígena, a escola vem contribuindo para sua assimilação pela cultura 
hegemônica. A perspectiva assimilacionista com que caracteriza a instituição pesquisada, gradativamente dissimula e marginaliza o repertório cultural indígena, contribuindo para o seu desaparecimento. Mediante a repetição dessa prática, corre-se o risco de que as crianças guarani, ao freqüentar os bancos escolares, valorizem o patrimônio alheio e envergonhem-se do próprio. Ao invés de reforçar sua identidade, podem passar a rejeitar aquilo que as constitui, a sua própria identidade. Avaliamos ser esta é uma questão urgente e que merece atenção por parte do coletivo escolar, visando estimular a reflexão sobre o crescente processo de fragmentação da comunidade e potencializar a inserção de novos conteúdos no currículo.

É evidente que a questão da identidade étnica, ou mesmo da nacionalidade, é um dos problemas mais complexos da cultura brasileira - afinal, quem é brasileiro? Ou o que é ser brasileiro? Ou índio? A escola, na opinião de Silva (2006), é ainda uma instituição com poder de interferir no processo de formação da identidade de nosso povo. Para que esse processo se dê a contento, o autor defende o desenvolvimento de ações pedagógicas que promovam uma séria análise dos elementos que contribuem para reforçar e naturalizar as diferenças. Na realidade investigada, considerar-se índio - e comportar-se tal como a sociedade envolvente espera que se comporte um índio - é condição sine qua non para que permaneçam no território demarcado da reserva indígena e tenham direitos reconhecidos, acesso a programas específicos das diversas esferas administrativas etc. Como se pode notar, o processo de assunção da identidade externamente conferida, quando não submetido à indagação pedagógica, contribui para a incorporação de estereotipias e fixação distorcida da identidade indígena. Nesse sentido, caso a escola reconheça, inclua e questione a forma com a qual o patrimônio da cultura corporal guarani é socializado na aldeia, estará contribuindo para a atribuição de valores positivos à própria identidade e ampliará os recursos para o combate aos mecanismos de assimilação e apagamento cultural oriundos da sociedade mais ampla.

A desarticulação entre os processos da cultura local e os processos da aprendizagem escolar constatados durante as observações prejudicam o diálogo entre a escola e a cultura indígena, tal como ocorre com a complicada relação entre Antropologia e Educação:

São duas discussões que raramente se encontram, apesar de terem por focos comuns os processos cognitivos; as histórias individuais de aprendizagem; as condições do exercício da criatividade; as relações entre razão, emoção e conhecimento; a produção e expressão de noções metafísicas, ontológicas (a humanidade, o cosmo...); a construção das identidades; percepção e visões de mundo, e tantos mais. (LOPES da SILVA citada por SILVA e FERREIRA, 2001a, p. 30).

No entanto, é necessário advertir que tal distanciamento é problema recorrente na maior parte das escolas brasileiras, portanto, não se trata de um fato específico das escolas indígenas. Não obstante, ponderamos que as conseqüências desta distância podem ser extremamente prejudiciais para a comunidade de Itaóca, devido às condições identificadas de fragmentação social e cultural.

A escola ocupa claramente um espaço fronteiriço entre a cultura guarani e a cultura da sociedade envolvente, seja no que respeita ao espaço físico, seja no interior do processo pedagógico. Conforme constatamos, apesar da valorização das danças enquanto ritual característico Guarani e da cultura lúdica que povoa o ambiente extra-escolar e que proporciona um certo diálogo entre as etnias da aldeia, tais conhecimentos não são validados pelo currículo da instituição, o que contribui para o estabelecimento de um 
processo de classificação e hierarquização cultural. Mediante a repetição do discurso que valoriza a escola enquanto ponte para inserção na vida pública, as crianças e adolescentes aprendem a atribuir sentidos positivos aos conteúdos que povoam o seu currículo. Porém, quando constatam que seu patrimônio cultural é negado pela instituição, restam-lhes duas alternativas, agarrar-se à cultura escolar e negar os conhecimentos que os identificam, ou resistir à aculturação da qual são vítimas e incorporar posturas de transgressão e rebeldia, reforçando as diferenças e afastando-se definitivamente da saudável experiência de intercâmbio que a escola poderá proporcionar.

No nosso entender, a presente investigação, quando denuncia os procedimentos "invisíveis" pelos quais a escola indígena desqualifica a cultura corporal guarani, colabora para que, no futuro, os educadores e educadoras que atuam em instituições semelhantes à da comunidade pesquisada, reflitam criticamente sobre $\mathrm{o}$ fato $\mathrm{e}$ trabalhem para sua transformação. Isso será possível caso cada escola indígena seja encarada como o espaço adequado para circulação democrática de saberes. Espaço que permita que seus alunos e alunas reconheçam dignamente sua identidade étnica e ultrapassem suas fronteiras, sem, no entanto, perder aquilo que os fundamenta e que poderá fazer da convivência com a sociedade envolvente algo que não os diminua nem diante de si mesmos, nem diante dos jurua.

\section{Referências Bibliográficas}

ANDRÉ, M. E. D. A. Etnografia da prática escolar. Campinas, SP: Papirus, 1995.

CANDAU, V. M. F. Pluralismo cultural, cotidiano escolar e formação de professores. In: Magistério: Construção cotidiana, Petrópolis: Vozes, 1997, p. 237-250.

DAOLIO, J. Da cultura do corpo. Campinas: Papirus, 1995.

GEERTZ, C. A interpretação das culturas. Rio de Janeiro: Ed. Guanabara, 1989.

GRUPIONI, L. D. B. Um território ainda a conquistar. In: FREIRE, J. R. B. et al. Educação escolar indígena em Terra Brasilis: tempo de novo descobrimento. Rio de Janeiro: Ibase, 2004. p. 33 a 45.

HALL, S. Da diáspora: identidade e mediações culturais. Belo Horizonte: UFMG; Brasília: Representação da UNESCO no Brasil, 2003.

KHAN, M. e AZEVEDO, M. O que está em jogo na educação escolar indígena? In: FREIRE, J. R. B. et al. Educação escolar indígena em Terra Brasilis: tempo de novo descobrimento. Rio de Janeiro: Ibase, 2004. p. 57 a 79.

KINCHELOE, J. L. e STEINBERG, S. R. Repensar el multiculturalismo. Barcelona: Octaedro, 1999.

LADEIRA, M. I. O caminhar sob a luz. Dissertação de Mestrado. Pontifícia Universidade Católica de São Paulo. São Paulo: PUC-SP, 1992.

. Espaço geográfico Guarani-MBYA: significado, constituição e uso. Tese de Doutorado. Faculdade de Filosofia, Letras e Ciências Humanas da Universidade de São Paulo. São Paulo: FFLCH, 2001.

LADEIRA, M. I. e AZANHA, G. Os índios da Serra do Mar, São Paulo: Nova Stella, 1988.

MAUSS, Marcel. As técnicas corporais. In: Sociologia e Antropologia. São Paulo: E.P.U./EDUSP, 1974. p. 209-233.

MOREIRA, A. F. B. Currículo, diferença cultural e diálogo. Educação \& Sociedade, vol.23, n.79, ago. 2002, pp. 15-38 
MOREIRA, A. F. B. e CANDAU, V. M. Educação escolar e cultura(s): construindo caminhos. In: Revista Brasileira de Educação, n.23, maio/jun/jul/ago., 2003. p.156-68.

MOURA, E. R. A iniciação ancestral da criança guarani Mbyá. Dissertação de Mestrado apresentada à Faculdade de Educação da USP. São Paulo: FEUSP, 2005.

Nande Arandu Pyguá. Memória Viva Guarani. São Paulo: Instituto Teko Arandu / MCD World Music, 2004. 1 CD-ROM.

Ñande Reko Arandu. Memória Viva Guarani. São Paulo: Projeto Memória Viva Guarani / MCD World Music, 2000. 1 CD-ROM.

NEIRA, M. G. e NUNES, M. L. F. Pedagogia da cultura corporal: crítica e alternativas. São Paulo: Phorte, 2006.

PEREIRA, A. Educação Multicultural: teorias e práticas. Porto: Asa, 2004.

SCHADEN, E. Aspectos fundamentais da cultura guarani, $3^{\mathrm{a}}$ ed., São Paulo: Editora Pedagógica e Universitária: Editora da Universidade de São Paulo, 1974.

SOARES, C. L. et. alli. Metodologia do ensino de Educação Física. São Paulo: Cortez, 1992

SILVA, A. L. e FERREIRA, M. K. L. (orgs.) Antropologia, história e educação - a questão indígena e a escola, São Paulo: Global. 2001a. p. 44-70.

SILVA, A. L. e FERREIRA, M. K. L. (orgs.) Práticas pedagógicas na escola indígena. São Paulo: Global, 2001b.

SILVA, T. T. A produção social da identidade e diferença. In: SILVA, T. T. (org.) Identidade e diferença: As perspectivas dos Estudos Culturais. Petrópolis: Vozes, 2006.

TASSINARI, A. M. I. Escola indígena: novos horizontes teóricos, novas fronteiras de educação. In SILVA, A. L. e FERREIRA, M. K. L. (orgs.) Antropologia, história e educação - a questão indígena e a escola, São Paulo: Global, 2001. p. 44-70.

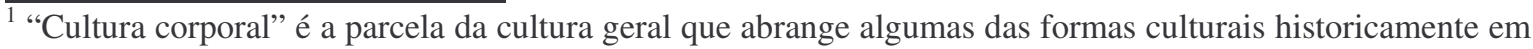
construção, tanto nos planos material quanto simbólico, mediante o exercício da motricidade humana - jogo, esporte, ginásticas e práticas de aptidão física, atividades rítmicas/expressivas etc. (Soares et al., 1992).

${ }^{2}$ Informações obtidas no decorrer das entrevistas com o vice-diretor.

${ }^{3}$ Para maiores informações sobre aspectos legais e definição de políticas públicas no estado de São Paulo, consultar a seguinte legislação: Resolução SE n ${ }^{\circ}$ 44/1997, Decreto no 45624/2001, Parecer CEE/CEB nº 592/2002, Deliberação CEE n 35/2003, Resolução SE nº 147/2003, Decreto nº 48530/2004.

${ }^{4}$ Segundo o Instituto Socioambiental (www.institutosocioambiental.org.br), com dados de 2003, os Guarani Nhandéva (ou Avá-Chiripá) estão associados aos Guarani Kayová, e constituem população de 8 a 10 mil pessoas no Brasil, concentrados no estado de MS, mas presentes em outros estados do Sudeste e do Sul do país. Há aldeias também no Paraguai e na Bolívia. Os Guarani-Mbya são aproximadamente 6 mil e possuem aldeias nos estados de RS, SC, PR, SP, RJ, ES. Há aldeias também na Argentina, no Paraguai e no Uruguai.

${ }^{5}$ Em conversas com diversas pessoas, Guarani e também não Guarani, percebemos o uso freqüiente da denominação Tupi-guarani, expressão que só aparece na literatura consultada em Ladeira e Azanha, ("Distinguem-se [os Mbyá] dos moradores mais antigos a quem chamam de Tupi-guarani ou Xiripá dizendo-se Guarani”, p. 15). Em saída de campo, uma das atividades do curso de Tupi Antigo do Depto. de Letras Clássicas da FFLCH-USP, ministrado pelo Prof. Eduardo Navarro, pudemos ter contato com indígenas da aldeia de Piaçaguera, em Peruíbe/SP. Uma parte das conversas aconteceu em guarani, nos dialetos guarani mbyá e, segundo alguns falantes da língua, "tupi-guarani”. Nestas conversas dois senhores demonstraram várias vezes a diferença, principalmente de pronúncia, entre um dialeto e outro, fazendo questão de distinguir "o guarani do tupi-guarani”. Segundo o prof. Eduardo, o "tupi-guarani” é uma língua ainda mais próxima do tupi antigo, usando expressões muito antigas. Outras pessoas, em conversas com o nosso grupo, mencionavam diferenças lingüísticas e de cultura entre um subgrupo e outro, usando sempre a expressão "tupi-guarani”. A expressão é utilizada também nos textos de divulgação do curso de Magistério Superior Indígena da FEUSP, e nos sítios eletrônicos da CENP, da CEI e da cidade de Mongaguá.
} 
${ }^{6} \mathrm{O}$ termo jurua é utilizado para denominar todos os não índios, a sociedade envolvente, os que falam português. Significa literalmente "boca cabeluda", o que traz à memória a imagem do colonizador europeu.

7 "Hoje, por que gravamos o CD? Porque o Guarani sempre foi dono da terra. Mas, através da invasão do Brasil, da colonização, o Guarani perdeu sua terra. (...) Através da gravação, a gente vai estar em forma de protesto" (encarte do CD-ROM Ñande Reko Arandu, Memória Viva Guarani. São Paulo: Projeto Memória Viva Guarani / MCD World Music, 2000. p. 2).

${ }^{8}$ Novamente a expressão "tupi-guarani" como designativo de etnia. Outras informações que julgamos relevantes, constantes do encarte do CD-ROM: "Neste CD estão registradas quatro modalidades da música guarani: Mitã Mongueá, ou acalantos; Kiringue Mborai, cantos infantis com temática religiosa; Kunhã Mimby, dueto de flautas de bambu tocadas exclusivamente por mulheres; e Kunhã Jerokya ou Dança do Tangará, tema instrumental executado com o mbaraká guaxu (violão) e rawé (rabeca), que acompanha esta modalidade de dança feminina. Este CD é resultado de um amplo movimento cultural intensificado a partir da gravação do CD-ROM Ñande Reko Arandu - Memória Viva Guarani, em 1998. Este movimento, iniciado pelas aldeias Tenondé Porã, Boa Vista, Ribeirão Silveira e Sapukai, motivou a revitalização dos corais infantis em várias aldeias guarani de estados do sudeste e do sul do Brasil, a composição de novos cânticos e a recuperação de modalidades que estavam sendo esquecidas como os acalantos e os temas de flauta feminina". Fonte: contracapa do CD-ROM Ñande Arandu Pyguá - Memória Viva Guarani. São Paulo: Instituto Teko Arandu / MCD World Music, 2004.

${ }^{9}$ Especificamente as obras organizadas por Aracy Lopes da Silva, da série Antropologia e Educação, publicadas em 2001.

${ }_{10}$ Tivemos oportunidade de observar o gestor cumprindo função de professor, porque, segundo seu depoimento, ele gosta de ensinar e espera que os professores, pouco experientes na função, possam observar "como se dá aula" e assim melhorar sua prática.

${ }^{11}$ Para intervir no comportamento dos alunos, o professor chama à atenção, recorda conversas anteriores sobre disciplina, toma objetos, adverte inúmeras vezes, faz ameaças (que vai contar pro pai, escrever bilhetes, por falta, mandar embora), zanga, grita, manda sentar, apela para que o ajudem, pois é um só "para duas turmas", repreende muitas vezes, fica irritado, compara um aluno com outro, pede que parem, discute com eles, muda alunos de lugar, resmunga, avisa o diretor, reclama, faz ironias, pede que fiquem quietos, chama um aluno de bobo, manda parar com brincadeiras, manda embora.

${ }^{12} \mathrm{Em}$ seu depoimento, este professor confirma o que o gestor havia relatado sobre como as situações de indisciplina escolar e excesso de faltas são tratadas nas reuniões da comunidade, fato que colabora significativamente para que comportamentos inadequados em sala de aula ocorram pouco e logo sejam reprimidos, sem contestação por parte das crianças.

${ }_{13}$ As falas do professor foram freqüentes quanto à necessidade de que essa criança não estivesse na sala, devido ao seu comportamento inadequado e porque ela não é aluna matriculada na escola, e que, portanto, segundo ele, não deveria estar lá.

${ }^{14}$ Alimento tradicional, parecido com um pão sírio, elaborado com farinha de trigo, mas que no passado era feito de milho.

${ }^{15}$ Há cerca de dois anos a aldeia foi contemplada com serviços de energia elétrica, pelo Program de Eletrificação Rural do governo federal, o que permitiu o acesso, para várias famílias, à TV, ampliando também o acesso ao rádio. Por ocasião da chegada da luz elétrica, algumas famílias Mbya afastaram-se do núcleo inicial da aldeia e construíram novas casas no interior da reserva, onde não há energia elétrica.

${ }^{16}$ A propósito do contato com as mulheres Mbya: a maioria delas sequer olhava para os pesquisadores. Em todas as oportunidades de contato, demonstravam total desinteresse. Houve uma tímida mudança ao longo dos meses em que as visitas aconteceram: olhares curiosos, sorrisos, cumprimentos de bom-dia, e a ligeira conversa descrita acima. A esse respeito, a frase de Schaden (1974, p. 76) é esclarecedora: "O que implica relações pessoais com gente estranha cabe de preferência ao elemento masculino".

${ }^{17}$ Embora dois depoentes manifestem a preocupação de realizar projetos pedagógicos que interajam com desejos presentes na aldeia de revitalização de práticas tradicionais (os grupos de canto e dança de ambas as etnias e o projeto de agricultura tradicional Mbya), durante todo o período de observação, tais idéias permaneceram na esfera das intenções.

Artigo recebido em 03/08/2008

Aprovado para publicação em: 31/07/09 